\title{
An Experimental Research on the Equalization of Basic Public Services in Huizhou City
}

\author{
Jiali Dai \\ School of Economics, Jinan University, Guangzhou, China \\ Email: daijiali99@126.com
}

Received 31 March 2016; accepted 24 April 2016; published 27 April 2016

Copyright (C) 2016 by author and Scientific Research Publishing Inc.

This work is licensed under the Creative Commons Attribution International License (CC BY). http://creativecommons.org/licenses/by/4.0/

(c) (i) Open Access

\begin{abstract}
In April 2012, the government of Guangdong Province selected Huizhou City as the first pilot city of this province to further promote comprehensive reform on the equalization of basic public services. Under the policy background, this paper selects pilot city, namely Huizhou, as an experimental research object, and selects three core indicators of the foundational education, social insurances and medical and health services to analyze. Specifically, this paper introduces governmental policies and security standards, and uses statistical analysis and coefficient of variation method to calculate and compare the index data for each county (district) of Huizhou City from 2008 to 2014. Overall, by studying current situation of the equalization of basic public services, we know the government of Huizhou has innovatively established a series of policies and measures and made considerable achievements in the process of implementation. Many coefficients of variation of indicators have declined after pilot project. But among the basic public services, the medical and health service develops slowly and it is serious unequal. The construction of medical and health service has become the bottleneck of the equalization of basic public services. Finally, according to the medical problem, the corresponding countermeasures are put forward.
\end{abstract}

\section{Keywords}

Huizhou City, Basic Public Services, Equalization

\section{Introduction}

In 1954, Samuelson proposed that products are divided into private goods and public goods, which everyone can consume public goods, and cannot reduce the other people's consumption [1]. The concept of "public services" 
is derived from the "public goods". Some scholars think that the concept of "public services" is the same as the "public goods", and there is no essential difference [2] [3]. And some scholars think what the government should do is the public services. Public services the government provides actually include private goods and public goods, so the concept of "public goods" can't cover the "public services" [4]. The basic public services are provided by the government, which depend on the level of economic and social development. It aims at ensuring the survival and development of all citizens.

In December 2009, the government of Guangdong Province prior issued the "Guangdong Provincial Planning Outline for Equalization of Basic Public Services (2009-2020)" (hereinafter referred as Guangdong Plan). In July 2012, the State Council of China issued the "National 12th Five-Year Plan for Equalization System of Basic Public Services" (hereinafter referred as National Plan), which uniformly specified the national minimum security standards of basic public services. Then, in May 2014, the Guangdong Provincial Department of Finance issued the "Guangdong Provincial Planning Outline for Equalization of Basic Public Services (20092020)” (Revised Edition) (hereinafter referred as Guangdong Revised Plan). One of the goals is striving for the higher equalization of basic public services among Chinese provinces. In April 2012, the government of Guangdong Province selected Huizhou City as the first pilot city of this province to further promote comprehensive reform on the equalization of basic public services. Under the policy background, this paper selects pilot city, namely Huizhou, as an experimental research object, and combines with the security standards of the above plans to specifically analyze the implementation of equalization of basic public services in Huizhou since the pilot. And what are the problems in the process of implementation to need further improvement?

The scope of basic public services includes education, employment, social insurances, medical and health services, family planning, housing security, culture, sports etc. For the broad meaning, it should include transportation, communications, public facilities, environmental protection, public safety, consumer safety, national defense and security etc. Due to the scope of the basic public services is a dynamic development process, the minimum boundary of its coverage is expanding with the economic development. So this paper selects the three most core indicators and the most urgent needs of the public, namely, foundational education, social insurances, medical and health services to analyze.

\section{Present Situation of Equalization of Basic Public Services in Huizhou}

Huizhou City is located in central and southern Guangdong Province of China, the northeast of the Pearl River delta. Huizhou City has more developed coastal areas, but also it has relatively backward mountainous areas. Huizhou City includes four districts and three counties, namely, Huicheng District, Huiyang District, Huidong County, Boluo County, Longmen County, Dayawan District and Zhongkai District. Among them, the Dayawan and Zhongkai District are nation-level development zones. Zhongkai District has the administrative permissions at district level just since 2010. It had been under the jurisdiction of Huicheng District before 2010. Municipal government strives to improve the people's happiness index in Huizhou.

For the basic social situation, in terms of per capita gross domestic product (GDP) in 2014, from high to low as follows: Dayawan (23.28 ten thousand Yuan), Zhongkai (12.75 ten thousand Yuan), Huiyang (5.69 ten thousand Yuan), Boluo (4.73 ten thousand Yuan), Huidong (4.75 ten thousand Yuan), Huicheng (4.71 ten thousand Yuan), Longmen (4.46 ten thousand Yuan). Dayawan and Zhongkai have a higher economic development, and the gap of other five regions is smaller. The resident populations concentrate in the Huicheng, Boluo and Huidong. Populations of Longmen and Dayawan are relatively less. In addition, the three counties of Huidong, Boluo and Longmen have more than $65 \%$ of the agricultural populations. The household registered populations of the other four districts are non agricultural residents.

\subsection{Foundational Education}

In 2014, for every district of Huizhou City, the gross enrollment rate of primary school and junior middle school reached $100 \%$. The city's acceptance rate of senior middle schools for junior middle school graduates is $99.01 \%$, and the city's acceptance rate of high college for senior middle school graduates is $92.96 \%$. During the pilot of equalization, municipal policies and measures on basic education mainly include: firstly, since the fall semester of 2012, Huizhou City has practiced the nutritional lunch program for the students from poor families who can get 800 Yuan subsidy each year according to the standard of 4 Yuan per student per day in total annual 200 days at school to calculation. A total of 23 thousand students get the subsidy. Secondary, in 2013, the number of new 
and renovated primary and middle schools is 18 in the whole city, so the government increases more than ten thousand enrollment quotas. Next, in 2014, for the education resources and quality are not balanced, municipal government of Huizhou further changes and improves the way, asked 134 urban schools and 155 rural schools pairing support. Rural teachers get training in urban school to enhance the educational quality of rural areas. And carry on the reform of education system. The teachers of part subjects such as English, music are unified distribution by the County Education Bureau instead of school, to ensure that rural schools have good teachers in class. Huidong County clear said that the $40 \%$ enrollment quotas of high quality senior middle school distribute to the graduates of rural junior middle school.

The teacher-student ratio can be used to measure resource of teacher. From Table 1 can be seen that among all districts of Huizhou City in 2014, the Longmen County gets the highest index value (5.81), followed by Huidong County (5.72). The lowest is Huiyang District (4.32), and value of Zhongkai District is relatively low (4.45). In recent years, the range and CV of teacher-student ratio in primary schools has reduced. The CV declines from maxima $16.30 \%$ in 2011 to $9.98 \%$, down about 6 percentage points, indicating that the equalization of teacher resource in primary schools is ascent among all districts.

In Table 2, the highest index value of teacher-student ratio in middle school still belongs to Longmen County (9.27) among all districts of Huizhou City in 2014, followed by Boluo County (7.78), and the lowest two counties are still Huiyang District (5.44) and Zhongkai District (6.45). The CV of teacher-student ratio in middle school had increased from $11.79 \%$ in 2012 to $13.81 \%$ in 2014, indicating the equal degree of teacher-student ratio in middle school is declining, and the unequal degree of teacher-student ratio in middle school is higher than the teacher-student ratio in primary school. An important cause of this phenomenon is that the teacher-student

Table 1. The teacher-student ratio of primary school in Huizhou City.

\begin{tabular}{|c|c|c|c|c|c|c|c|c|c|c|}
\hline Distr & Huicheng & Huiyang & Huidong & Boluo & Longmen & Dayawan & Zhongkai & Average & Range & CV (\%) \\
\hline 2008 & 4.35 & 4.68 & 4.20 & 5.42 & 6.29 & 6.33 & - & 4.75 & 2.13 & 13.55 \\
\hline 2009 & 4.55 & 4.70 & 4.66 & 5.74 & 6.86 & 5.96 & - & 5.02 & 2.31 & 13.17 \\
\hline 2010 & 4.63 & 4.66 & 5.24 & 5.77 & 7.41 & 5.24 & - & 5.19 & 2.78 & 13.37 \\
\hline 2011 & 4.60 & 4.30 & 5.63 & 5.82 & 7.64 & 4.87 & 4.30 & 5.19 & 3.34 & 16.30 \\
\hline 2012 & 4.56 & 4.12 & 5.53 & 5.59 & 7.37 & 4.67 & 4.23 & 5.04 & 3.25 & 15.94 \\
\hline 2013 & 4.86 & 4.31 & 5.60 & 5.37 & 6.49 & 4.69 & 4.26 & 5.09 & 2.68 & 12.80 \\
\hline 2014 & 4.86 & 4.32 & 5.72 & 5.13 & 5.81 & 5.23 & 4.45 & 5.03 & 1.49 & 9.98 \\
\hline
\end{tabular}

a) data source: the data calculated according to the statistical yearbook of Huizhou City from 2009 to 2015. The data of Zhongkai District from 2008 to 2010 contained in Huicheng District. b) teacher-student ratio of primary school, namely, the number of teachers per hundred students of primary schools $=$ (The number of primary school teachers/the number of primary school students $) \times 100$. c) Range $=$ maximum-minimum. Range is to describe the maximum gap of data. The bigger value of range, the greater degree of dispersion; otherwise, the degree of dispersion is smaller. d) CV is the abbreviation of coefficient of variation. $\mathrm{CV}=$ standard deviation/average, $\mathrm{CV}$ is used to compare the different indexes. The value of $\mathrm{CV}$ is bigger, the data of the groups is more discrete, and the difference is bigger; otherwise, the discrete degree is smaller.

Table 2. The teacher-student ratio of middle school in Huizhou City.

\begin{tabular}{|c|c|c|c|c|c|c|c|c|c|c|}
\hline $\begin{array}{l}\text { District } \\
\text { Year }\end{array}$ & Huicheng & Huiyang & Huidong & Boluo & Longmen & Dayawan & Zhongkai & Average & Range & CV (\%) \\
\hline 2008 & 5.22 & 4.82 & 4.33 & 5.72 & 6.74 & 5.71 & - & 5.16 & 2.41 & 12.84 \\
\hline 2009 & 5.40 & 5.38 & 4.79 & 5.91 & 6.89 & 5.72 & - & 5.47 & 2.10 & 9.93 \\
\hline 2010 & 5.81 & 5.19 & 4.72 & 6.09 & 6.99 & 5.75 & - & 5.58 & 2.27 & 11.49 \\
\hline 2011 & 6.15 & 5.21 & 4.92 & 6.28 & 7.51 & 5.89 & 5.61 & 5.77 & 2.59 & 12.40 \\
\hline 2012 & 6.46 & 5.65 & 5.44 & 6.94 & 8.02 & 6.10 & 5.62 & 6.22 & 2.58 & 11.79 \\
\hline 2013 & 6.80 & 5.58 & 6.20 & 7.44 & 8.74 & 7.12 & 6.08 & 6.64 & 3.16 & 12.37 \\
\hline 2014 & 7.01 & 5.44 & 6.89 & 7.78 & 9.27 & 7.61 & 6.45 & 6.93 & 3.83 & 13.81 \\
\hline
\end{tabular}

a) teacher-student ratio of middle school, namely, the number of teachers per hundred students of middle schools = (The number of middle school teachers/the number of middle school students) $\times 100$. Middle schools include junior middle schools and senior middle schools. 
ratios in primary school of Longmen and Boluo have declined since the respective maxima value in 2011. Otherwise, the teacher-student ratios in middle school of these two counties have risen fast. Teachers of primary schools flow to middle schools, so lead to the reduction of primary school teachers, and the increase of middle school teachers. The per capita GDP ranks of Longmen, Boluo and Huidong are lower, but on the basic education, the ranks of teacher-student ratios for these three counties are high rather than low. However, from the view of teacher's quality, a large number of good primary school teachers were promoted to middle schools in Longmen and Boluo County. The quality of primary school teachers will decrease, in addition, are promoted teachers of primary school competent for the curriculums of middle school? Therefore, the quality of education is questionable in these two counties.

Governmental fiscal expenditure on education has been characterized by high investment and steady growth. Even the economy develops relative slowly for Huidong, Boluo and Longmen, educational expenditure of these three counties has been maintained at a high level. For Longmen County as an example, in 2014, the proportion of education spending in public finance budget expenditure is $25.56 \%$, and per student spending including kindergartens, primary schools and middle schools reached 10670 Yuan, which rank is at the forefront among all counties. From the year of 2008 to 2014, the average annual growth rate of educational spending is up to $22.96 \%$. So we can see that slow growth of economy did not result in low student spending, reflecting the governments at all levels have always highly valued education. For Huizhou City, the current problem of basic educational equalization is not the lack of access to accept education, but the imbalance of educational resources and quality. For a nation, even more so, the quality of teaching in remote areas is low, and it is difficult to retain good teaching personnel. In addition to the governmental investment to reduce the educational burden of low-income families, the difficulty and focus is providing teaching personnel and educational facilities for remote areas, so that every student can get high quality education even living in different regions.

\subsection{Social Insurances}

Social insurances include social assistance, pension insurance, medical insurance, maternity insurance and unemployment insurance to provide a social safety net for the residents. This paper mainly introduces three kinds of social assistance, pension insurance and medical insurance.

(1) Social assistance. Let the elder, the disabled, orphans and other vulnerable groups live with dignity and equally participate in social development, which is the most essential principle of "equalization of bottom line". On social assistance for Huizhou city the mainly measure is continuous improving guarantee standards to directly increase their disposable income. Starting from January 2015, the livelihood assistance level raises again, such as the minimum living subsidy standard increased from the per person per month 482 Yuan to 550 Yuan; living subsidy standard for orphans increased from 1200 Yuan per person per month to 1290 Yuan; care subsidy standard for the severe disabilities increased from per person 1200 Yuan a year to 1800 Yuan. In addition, the government of Dayawan District actively explores the first batch of pilot. The government provides free lunch delivery service according to the standard of 15 Yuan per person per day for the more than 60 years old residents living difficult for a year.

(2) The basic pension insurance. Huizhou City has two kinds of basic pension systems. One of the kinds is residents' pension insurance including rural residents and non-working urban residents. The other is urban workers pension insurance. The number of residents' pension insurance has achieved the coverage of all residents at the first half of 2012 in Huizhou city. The pension of residents' pension insurance is composed of fundamental pension paid by the government and individual payment pension. In the Guangdong Revised Plan, the Guangdong provincial government requires the minimum standard of the fundamental pension is 65 Yuan per person per month with an annual average growth of more than $10 \%$, and makes a clear regulation that the minimum standard in 2015 is no less than 100 Yuan per month, which is far higher than the national uniform standard of not less than 55 Yuan. Therefore, from July 1, 2014, the fundamental pension standard of Huizhou City improved from 90 Yuan to 105 Yuan paid by the national financial subsidies of 27.5 Yuan, the provincial financial subsidies of 26.25 Yuan, the city financial subsidies of 28.125 Yuan and the county financial subsidies of 23.125 Yuan. Since July 1, 2015, the fundamental pension standard of Huizhou City further has increased to 125 Yuan more than the provincial standard.

(3) Basic medical insurance. The basic medical insurance system in Huizhou is composed of residents' medical insurance including urban and rural residents and workers medical insurance. According to the residents vo- 
luntarily choose to pay, the residents' medical insurance divides into two types of A-type and B-type. In 2014, A-type needs to pay 30 Yuan per person per year by the individual, and B-type needs to pay 150 Yuan. Whether it is A-type or B-type, the government has to provide financial subsidies of 340 Yuan per person per year for every resident' medical insurance, which becomes an important source of income for residents' medical insurance fund.

From the number of insured persons, the insured rate of city's basic medical insurance has reached $100 \%$. In 2014, the insured number of workers pension insurance is 212.91 ten thousand, about twice the insured number of residents' pension insurance for Huizhou City. But on the medical insurance, the insured number of workers medical insurance is only 166.68 ten thousand people, about $63.8 \%$ of the insured number of residents' medical insurance. Overall, 61\% of people choose to participate in residents’ medical insurance for which $65.36 \%$ of the residents choose to a higher B-type to insure in the city.

Due to large insured number of residents' medical insurance and high financial subsidy standard, led to financial subsidy of governments at all levels on the residents' medical insurance is up to 0.97 billion Yuan in 2014 of Huizhou, far higher than the financial subsidy of 0.64 billion Yuan on residents' pension insurance. Plus the financial subsidy income, the current balance of residents' medical insurance fund is only 76.4 million Yuan in 2014 of Huizhou, so the current fund income is slightly larger than the current expenditure. But the requirement of Guangdong Revised Plan is that financial subsidy standard of governments at all levels on the residents' medical insurance increases to over 360 Yuan per person per year at 2015. Therefore, financial subsidy standard of Huizhou city will add at least 20 Yuan to the existing basis of 340 Yuan, which will bring some pressure on the governmental fiscal expenditure. In addition, Huizhou city also further adjusts the policies of medical insurance. Such as from January 1, 2015, the individual payment standard of A-type on residents' medical insurance raised from per person per year 30 Yuan to 80 Yuan, and the B-type raised from 150 Yuan to 170 Yuan. The improvement of the financial subsidy standard and the individual payment standard will directly expand the income scale of the residents' medical insurance fund. Therefore, fund expenditure is also adjusted accordingly. The medical insurance fund improves the reimbursement maximum of annual hospitalization expenses for the insured, increases the hospitalization reimbursement programs and adjusts higher hospitalization reimbursement ratio of medical insurance. The income and expenditure expansion of the residents' medical insurance fund can further play the role of spread risk for residents.

The medical reimbursement policies of China adopt three principles of "starting line”, “co-payment” and “cap”, which the main purpose is to avoid moral risk, prevent drug abuse and keep the balance of fund. In 2014 of Huizhou, the hospital inpatients were reimbursed average 9910.70 Yuan per time for medical expenses, and in 2013 of Huizhou, the average medical expense by individual of hospital inpatient is 6545.7 Yuan. According to these two data estimate, the city's actual reimbursement ratio of medical insurance including residents and workers medical insurance is about 60\%. Residents' medical insurance has a big gap for workers medical insurance on the financing and reimbursement. Especially the actual reimbursement of A-type is lower. The current actual medical reimbursement ratio is at the low level.

\subsection{Medical and Health Services}

Except medical insurance, the construction of medical and health services is a main aspect of basic public services as important as education, which determines the quality of medical services and the distribution of medical resource in each district. On the health care, the governmental current work completed better is major public health service projects, including free carrying out fertility inspection and preventable vaccination, preventing and controlling infectious disease. In Huizhou City, on the national immunization program the coverage of first class vaccine is $100 \%$ and inoculation rate of single vaccine is above $95 \%$. The main inequality of basic health service is the imbalanced distribution of medical resources.

The number of doctors per thousand residents shows an upward trend. The goal of the number of doctors per thousand residents for Huizhou in 2015 is to reach 1.9. From the Table 3, in fact, the index reached 1.93 at the end of the 2012 year, ahead three years of schedule to achieve the planning object, and in the end of 2014 it has risen to 2.12. The index of Huicheng District in 2014 reached 3.53 ahead of other counties. On the contrary, the index value of Zhongkai District is obviously lower. The reason is that the Zhongkai District has set up a shorter time, so basic public services are not perfect. Because the distance of Huicheng and Zhongkai District is near, so it can ease part of the pressure. Besides, the index values of Huidong, Boluo, Longmen County are at a low level, 
Table 3. The number of doctors per thousand residents for each county in Huizhou City.

\begin{tabular}{cccccccccccc}
\hline District & Huicheng & Huiyang & Huidong & Boluo & Longmen & Dayawan & Zhongkai & Average & Range & CV (\%) \\
\hline Year & & & & & & & & & & & \\
2008 & 1.98 & 1.45 & 0.92 & 0.85 & 0.90 & 0.73 & - & 1.30 & 1.25 & 38.63 \\
2009 & 2.07 & 1.79 & 1.13 & 0.89 & 0.92 & 0.78 & - & 1.44 & 1.30 & 36.33 \\
2010 & 2.42 & 1.89 & 1.15 & 1.00 & 0.99 & 0.83 & 0.78 & 1.47 & 1.64 & 42.88 \\
2011 & 2.62 & 2.01 & 1.19 & 1.22 & 1.11 & 0.83 & 0.69 & 1.59 & 1.93 & 42.83 \\
2012 & 3.18 & 2.43 & 1.50 & 1.33 & 1.53 & 1.52 & 0.63 & 1.93 & 2.55 & 43.97 \\
2013 & 3.36 & 2.45 & 1.60 & 1.44 & 1.65 & 2.00 & 0.94 & 2.07 & 2.41 & 40.32 \\
2014 & 3.53 & 2.45 & 1.61 & 1.48 & 1.70 & 1.84 & 0.92 & 2.12 & 2.60 & 42.16 \\
\hline
\end{tabular}

a) data source: the data calculated according to the statistical yearbook of Huizhou City from 2009 to 2015. The data of Zhongkai District from 2008 to 2010 contained in Huicheng District. b) The number of doctors including professional and assistant physicians. c) Unit: doctors/one thousand residents.

which Boluo County is only 1.48 in 2014.

The goal of Huizhou in 2015 is to reach 4 medical beds per one thousand residents. From Table 4, we can be known, the city reached 4.07 at the end of 2013 two years ahead of schedule to achieve the goal, and in 2014 it further rose to 4.26. Among districts, the index value of Huicheng District in 2014 reached 7.99, which is only a district reaching more than 4, namely, the only one among counties over the average. Except Zhongkai District, the index values of Longmen, Huidong and Boluo County are still at lower level, which Longmen County is only 2.94. Uneven distribution of resources among districts results in the coefficient of variation of the doctors and hospital beds per one thousand residents at a high level, and there are no downward trends.

\section{Problem Analyses on the Equalization of Basic Public Services in Huizhou}

Overall, in the process of implementation, the government of Huizhou has innovatively established a series of policies and measures and has made considerable achievements. From the status of basic public services in Huizhou City, the fundamental education needs to further improve the equalization of quality education. Governments have always attached great importance to education, so it has a higher proportion of financial investment and a steady growth all the time. For the majority of ordinary families, education spending is tolerable, and does not produce too much effect of inhibitory consumption, so the gap of education among districts is still in an acceptable range. On the social insurance, the governmental social assistance for special groups, basic pension and medical insurance are almost coverage of the whole city, and the subsidy standards continue to improve. In addition, the system construction of education and social insurance has been more perfect. But the coefficients of variation of the doctors and hospital beds per one thousand residents are far higher than $13.81 \%$ of the teacher-student ratio for middle school, which shows that the unequal degree of medical and health services is far higher than the inequality of education. At present, most of the medical resources are concentrated in the urban districts, and the rural medical resources are relatively insufficient. The professional and technical personnel, especially general practitioners are lack, and lower medical technology level is restricted to the development of primary medical and health institutions. Although health care is a kind of private goods, the high cost of medical care becomes the focus of public concern, so it becomes the livelihood issues for governments to solve. The construction of medical and health has become the bottleneck of the equalization of basic public services. In the follow-up of the equalization implementation, medical and health services should become the focus of governmental priority among basic public services.

\section{Countermeasures and Suggestions to Promote the Equalization of Basic Public Services in Huizhou City}

(1) Strengthen the development of professional and technical doctors for primary medical and health institutions. Rural doctors are the most close to rural residents and they are the health guardian of rural residents. Strengthen the development of rural doctors and improve medical skills to achieve the goal of hospital admission rate more than $90 \%$ within the county. It has important significance for rural residents to have convenient, 
Table 4. The number of hospital beds per thousand residents for each county in Huizhou City.

\begin{tabular}{lccccccccccc}
\hline District & Huicheng & Huiyang & Huidong & Boluo & Longmen & Dayawan & Zhongkai & Average & Range & CV (\%) \\
\hline Year & & & & & & & & & & & \\
2.40 & 2.64 & 1.81 & 2.00 & 1.97 & 0.86 & - & 2.44 & 2.54 & 29.99 \\
2008 & 3.17 & 2.96 & 2.14 & 2.17 & 2.11 & 0.80 & - & 2.54 & 2.37 & 23.40 \\
2010 & 4.13 & 3.16 & 2.13 & 2.29 & 2.47 & 0.74 & 0.89 & 2.65 & 3.39 & 39.57 \\
2011 & 4.49 & 3.35 & 2.31 & 2.26 & 2.80 & 0.73 & 0.94 & 2.83 & 3.76 & 41.43 \\
2012 & 6.03 & 3.77 & 2.74 & 2.74 & 2.88 & 3.46 & 2.10 & 3.69 & 3.93 & 38.81 \\
2013 & 7.51 & 3.89 & 2.99 & 3.03 & 2.91 & 3.50 & 0.84 & 4.07 & 6.67 & 52.18 \\
2014 & 7.99 & 3.87 & 3.14 & 3.16 & 2.94 & 3.42 & 1.01 & 4.26 & 6.98 & 53.34 \\
\hline
\end{tabular}

a) Unit: hospital beds/one thousand residents.

cheap and safe basic medical service. The governments should pay great attention to cultivate rural medical professionals willing to retain in rural area.

(2) Establish civilian price of medical and health services. Actively explore an effective mechanism to reduce the medical expenses and burden of the public and further improve the accessibility of basic medical and health services. The government of Huizhou should promote the construction of "civilian medicines price, civilian clinic price, and civilian hospital price”. Select some medicines and regulate the prices not exceeding a certain standard. And some single disease medical expenses of clinics should lower than ordinary outpatient. The clinic and hospital of civilian prices are mainly provided for poor households and other disadvantaged groups, and it is encouraged to give consideration to the general population. The current biggest burden of residents is from medical expense. Being liberated from the high medical expenses is still a tough task for the government.

(3) Public hospital reform. Public hospital at county level is the link between urban and rural medical service system. At present, the medicine prices of public hospitals generally increase $15 \%$ on the basis of the purchase price and then sell to patients, in order to subsidize hospital income. The more medicines the doctor prescribed, the hospital's medicines income is higher. The key to the reform of public hospitals is to break dependent medicines revenue for hospitals. Public hospitals at county level should reduce medicines price selling zero profit. In addition, strictly control unreasonable growth of medical expenses and the massive usage of antimicrobial drugs and reduce the amount of outpatient infusion. It is strictly prohibited by unreasonable decomposition of the prescription and cannot increase the use of drugs to aggravate the medical burden of patients.

Equalization of basic public services can ease the problems among regions caused by unbalanced development, highlight the social fairness and justice, and it is an important part of the harmonious society. The goal of equalization is that each individual no matter where they are can share the roughly equal basic public services. But the current equalization is still in a primary level. This paper selects Huizhou City as a sample, which has the important reference significance for the further promoting the equalization of basic public service.

\section{References}

[1] Samuelson, P.A. (1954) The Pure Theory of Public Expenditure. Review of Economics and Statistics, 36, 387-389. http://dx.doi.org/10.2307/1925895

[2] Zhang, X. (2004) Doubts Analysis of Public Economics. Finance \& Trade Economics, No. 4, 47-53.

[3] Gao, P.Y. (2004) Publicity: The Essence of Public Finance. People’s Daily, 2004-10-22.

[4] Liu, S.X. (2007) The Goal of Equalization of Basic Public Services Is to Promote the Equality of Residents' Consumption. China State Finance, No. 7, 72-73. 